\title{
Applying case based reasoning for prioritizing areas of business management
}

\author{
Miguel A. Carmona ${ }^{a}$, Julio Barbancho ${ }^{b}$, Diego F. Larios ${ }^{b}$, Carlos León ${ }^{b}$ \\ a IAT (Andalusian Institute of Technology), Seville, Spain \\ $\mathrm{b}$ Department of Electronic Technology, University of Seville, Spain
}

A B S T R A C T

\section{Keywords:}

CBR

Expert systems

Business management areas

Knowledge based system

\begin{abstract}
Determining the importance of different management areas in a company provides guidance about the needs of increasing the analysis and actions focuses in particular topic. To do it, it is necessary to decompose the management in a coherent set of specific management areas and provide a way that allows the company to determine the importance of these areas for them. This paper presents a novel system that guides companies to obtain a classification of important management areas for them. It is focused on the use of a case based reasoning system because the variability and the evolution of companies as time passes requires using techniques with learning capabilities. The proposed system provides an automatic self-assessment system that provides companies an ordered list of their most important management areas. This system was implemented a year ago for the evaluation of Spanish companies. Currently, it is in production providing relevant information about the management areas of these companies.
\end{abstract}

\section{Introduction}

Business management involves making decisions about the activities and the resources, available or needed, in order to achieve planned results. Therefore, companies need to use systems for measuring and evaluating their performances. These systems have been adapted and have evolved over time due to the need for companies to make the right decisions to improve the management on the basis of an appropriate assessment (Mavroidis, Toliopoulou, \& Agoritsas, 2007; Neely et al., 2000).

Among the most used assessment methods, it is possible to identify some that are based on excellence models like the European Foundation for Quality Management Model (EFQM) (Conti, 2007) or the Malcolm Baldrige in the United States (De Carlo \& Sterett, 1990). Both provide a method to obtain an evaluation of a complete company. But some authors have criticized these models because the amplitude of its considerations does not allow obtaining the best available results (Conti, 2007). This is why some authors (Zink \& Schmidt, 1998) have been suggested their own self-assessment models. Moreover, some authors (Bititci, Turner, \& Begemann, 2000) think that the Performance Management System (PMS) should have a dynamic adaptation mechanism. Classical self-assessment models for companies lack this. Generally they are static and heterogeneous, losing precision.

To avoid it, management is usually divided into specific areas that allow a greater command and control of the companies. These kinds of grouping management areas in organizations are aimed at

\footnotetext{
* Corresponding author. Tel.: +34 9545528 38; fax: +34 954552833 . E-mail address: jbarbancho@us.es (J. Barbancho).
}

minimizing the costs of coordination and communication (Mintzberg, 1979). In this way, companies determine and define their own management areas to monitor and control, such as quality management, production, logistics, R\&D, etc. These areas and their importance depend on each company, but generally it is possible to define a common set of them (Mintzberg, 2010; Pride, Hughes, \& Kapoor, 2009), which covers all the management, permitting making relevant decisions about the whole company. Related to this, some authors have proposed local models to self-assess one of these management areas, even if it means a loss of the general overview. For example (van der Wiele et al., 1996) proposes a self-assessment model for quality management.

However, a comprehensive and integrated view of the management of the company can be obtained by performing individual analysis of different management areas based on their importance. But the importance of management areas may differ from one company to another. For example, in some companies logistics management may be the most important area, while in others people management may be more critical. Therefore, the importance of each management area depends on the nature and characteristics of the business, and it is difficult to analyze or model. Moreover this importance can change over time depending on the evolution of the company, the sector to which it belongs and the macroeconomic situation.

Due to the complexity of determining the most important management areas for a company, one or several experts, depending on the characteristics of the company and the expert experience with other similar companies, usually do it. Moreover, the coordination between the company and the expert evaluation usually requires a lot of time. 
The proposed system overcomes this issue, with a real-time self-assessment system that provides companies a comprehensive list of management areas ordered by importance. The system is designed without losing sight of obtaining an overall assessment. This is done by applying a strategy of ordered evaluation of the different areas of business management and subsequent aggregation.

The proposed module is based on an automated system that allows real-time self-assessment of companies using a case-based reasoning (CBR) expert system which can learn from the companies that use the system.

The rest of the paper is divided into the following blocks. Section 2 discusses the application of computational intelligence to the field of business management. Section 3 develops the model proposed. The results are described in Section 4. Finally, Section 5 summarizes the conclusions and future work in which the authors are currently working to improve the proposed system.

\section{Computational intelligence applied to business management}

Computational intelligence (Engelbrecht, 2007) is a set of techniques that simulates the methodology used by humans to solve problems.

They are especially useful in cases where there is no model, or the model is complex, for example as in intrusion detection (Wu \& Banzhaf, 2010), pattern recognition (Nikravesh, 2004) vision (Munder \& Gavrila, 2006) or data mining (Velmurugan, 2011).

Moreover some of these techniques are useful in cases where you have a dynamic system. I.e., a model that varies or changes over time. In these kinds of systems, instance-based (Hüllermeier, 2007) approaches, such as case-based reasoning systems, are especially useful.

Business management is an area that requires dynamic and complex model. Due to this, it is common to apply these kinds of techniques to this area; for example, evaluating the performance of a company (Lam, Ip, \& Lau, 2009), predicting cycles (Lin \& Pai, 2010) or evaluating crises (Chen \& Hsiao, 2008).

\subsection{CBR applications}

Case based reasoning (CBR) is a branch of instance-based computational intelligence. It started with the work of Schank in 1982 (Shiu \& Pal, 2004).

CBR systems are based on the case-based inference hypothesis (CBI) (Hullermeier, 1999) which holds on "similar problems should have similar solutions". This type of reasoning is similar to that commonly used by people to solve problems; using memories of similar past experiences to solve new problems.

Due to its ability of adaptation to changing scenarios using previous results, this technique is widely used to develop support systems for business management (Brown \& Gupta, 1994). For example, it has been used successfully in areas such as business process monitoring (Montani, Leonardi, \& Bramer, 2010) or business failure detection (Li \& Sun, 2011; Lin, Yeh, \& Lee, 2011; Yeh, Chi, \& Hsu, 2010), where they have been proven to be quite effective.

This paper applies CBR technology to the detection of the main management business areas of a company. This is a novel approach, useful for companies to determine the management areas which they need to enforce to increase their productivity.

The use of a CBR in the proposed system allows dynamic responses in changing scenarios. It permits including inferred experience from other companies that have used the proposed system before.

\section{Description of the proposed system}

The proposed system could be described as a general module that relates a series of entries, called characterizing factors of the enterprise $\left(X_{j}\right)$, with a number of management areas $\left(A_{i}\right)$ ordered consistently according to their strategic importance for the management of a company. Therefore the proposed system seeks a model that relates the importance on management areas with the characterizing factors, e.g.:

\section{Importance $\left(A_{i}\right)=f\left(X_{j}\right)$}

Due to the characteristic of the business sector, this relationship model must hold the following characteristics:

- It must provide to companies a list of business management areas ordered by importance, as a result of a self-assessment of a number of characterizing input factors.

- It must provide an aid to companies to make decisions about which areas may require more attention, and therefore, which areas may be subject to a specific assessment to determine the state of maturity of the company.

- It must be able to learn easily from past experience, obtained from self-assessment of other companies.

- It must easily adapt to changes that occur in companies due to external reasons, such as the situation of the company sector.

- It must store knowledge in an easy way to understand and maintain by an expert.

- It must be able to provide a real-time response.

- It must allow changes in the learning experience without a full reconfiguration of the system.

Multiple techniques have been considered in order to obtain a system that integrates all these objectives, such as neural networks, Bayesian networks, fuzzy logic, Markov chains, reinforcement learning, rules-based system, case-based reasoning, etc. CBR system has been chosen due to the fact that it meets all the above requirements. Moreover $\mathrm{CBR}$ does not require a training step to learn new knowledge. CBR system stores the knowledge clearly, allowing an expert to maintain it easily.

Fig. 1 shows the structure of the system. It depicts the different actors involved in the proposed system: the company that makes the self-assessment request; the server that integrates the CBR system and the expert responsible for managing the acquired knowledge. This figure also associates each one of the CBR typical steps with the actors involved in the system. The steps are the following:

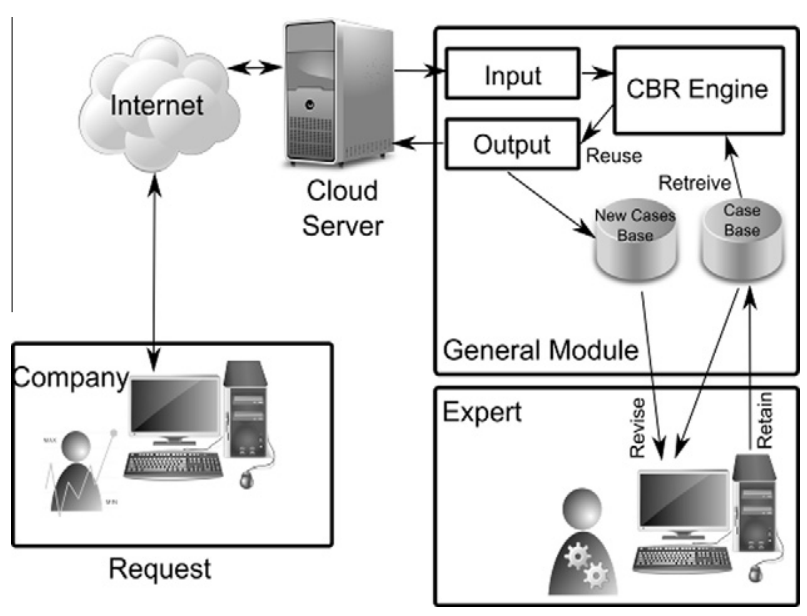

Fig. 1. Architecture of the proposed CBR system. 
- Retrieve: it is made by the company when it sends a new selfassessment. It consists in obtaining the most similar cases to the new inputs from the case based according to the nearest neighbor criterion.

- Reuse: it consists in obtaining the outputs, i.e., the ordered list of the management areas, using the retrieved cases.

- Revise: the system expert administrator menu provides an interface that allows an expert to manage the case base and revise the new proposed solutions.

- Retain: after reviewing the cases by the expert, it can be included to the case base.

\subsection{Inputs variables}

These variables were obtained through the participation of an experts committee. Considering an initial literature review (Ahmed \& Abdalla, 2002; Miles \& Snow, 2003; Porter, 2011), the experts committee has focused on the identification of the different characterizing factors of companies $\left(X_{j}\right)$ using group dynamics, such as brainstorming techniques.

Using these methods, a list of characterizing factors was obtained. This list was reduced to a final list of 23 characterizing factors (Table 1) using affinity diagrams (kJ Method) (Kawakita, 1986).

The characterizing factors can be classified into five main groups: the sector to which the company belongs, the negotiation with stakeholders, general aspects related to the size of the company, the strategy of the company (which can be divided into: the market, the basis of competition and the operations) and the resources.

This list has been confirmed by the experts committee using a technique based on the Kendall consensus method (Cook \& Seiford, 1982), to allow the weighting of each of the 23 factors, from the addition of individual preferences expressed by the different experts.

The weight of each factor $\left(\alpha_{i}\right)$ represents its relevance to determine the most important management areas in a company. These parameters are used to calculate the similarity between cases, as described in Section 3.4.1.

For each one of these 23 characterizing factors, an entire value in [1-5] range has been defined, according to ISO 9004:2009 maturity levels.

Using that, every company that uses the proposed system is evaluated considering these 23 characterizing factors, each one with a qualification in [1-5] range and considering the sector of the company.

\subsection{Outputs variables}

Following a similar process used to obtain the input variables (Kawakita, 1986), a list of management areas have been obtained as the output variables.

After adding, 14 management areas were obtained. These areas are described in Table 2. It can be classified into three groups: value chain related areas; support processes related areas and crosssectional areas.

Based on the results obtained by the committee of experts, these fourteen business management areas can be used to broadly evaluate companies. Moreover these areas are consistent with the corporate organization proposed by Mintzberg (1979).

The goal of the proposed system is to classify these fourteen management areas for each self-assessment company. Using that information, a complete evaluation strategy can be applied in every company, through a detailed analysis of its most important management areas. It could help to improve the management of the company.

\subsection{Case-base}

CBR requires a validated case base as information source to provide the proposed solutions. In the proposed system, these cases involve real information obtained from self-evaluated companies. Each case contains the following information:

Table 1

Characterizing factors of a company.

\begin{tabular}{|c|c|c|}
\hline $\begin{array}{l}\text { Sector (group of companies in which a Company competes or may } \\
\text { compete) }\end{array}$ & $\begin{array}{l}\mathrm{X} 1: \\
\mathrm{X} 2: \\
\mathrm{X} 3: \\
\mathrm{X} 4:\end{array}$ & $\begin{array}{l}\text { Technological level of the sector } \\
\text { Level of differentiation within the sector characteristic } \\
\text { Level of rivalry } \\
\text { Difficulty of imitation }\end{array}$ \\
\hline Negotiating power & $\begin{array}{l}\text { X5: } \\
\text { X6: } \\
\text { X7: } \\
\text { X8: }\end{array}$ & $\begin{array}{l}\text { Requirements revel (legal inl.) regarding customers } \\
\text { Requirements revel (legal inl.) regarding providers } \\
\text { Requirements revel (legal inl.) regarding community } \\
\text { Requirements revel (legal inl.) regarding people }\end{array}$ \\
\hline General aspects & $\begin{array}{l}\text { X9: } \\
\text { X10: } \\
\text { X11: } \\
\text { X12: }\end{array}$ & $\begin{array}{l}\text { Number of employees } \\
\text { Turnover (income) } \\
\text { Asset values } \\
\text { Capital structure (field of membership capital - family, cooperative, ..., multi) }\end{array}$ \\
\hline Strategic & $\begin{array}{l}\text { X13: } \\
\text { X14: } \\
\text { X15: }\end{array}$ & $\begin{array}{l}\text { Geographical scope of action (market) } \\
\text { Product diversification level (portfolio) } \\
\text { Geographical dispersion of production plants, facilities and/or centers } \\
\text { (number of centers, distance between centers) }\end{array}$ \\
\hline Base of competition (generic strategies) & $\begin{array}{l}\text { X16: } \\
\text { X17: }\end{array}$ & $\begin{array}{l}\text { Level of differentiation of products and services } \\
\text { Level of competence in cost of products and services }\end{array}$ \\
\hline Transactions & $\begin{array}{l}\text { X18: } \\
\text { X19: }\end{array}$ & $\begin{array}{l}\text { Percentage of outsourcing of activities } \\
\text { Technological level of processes (level of advance of applied technology - } \\
\text { traditional, advanced; level of complexity of the technology applied - low, medium, high) }\end{array}$ \\
\hline Resources & $\begin{array}{l}\text { X20: } \\
\text { X21: } \\
\text { X22: } \\
\text { X23: }\end{array}$ & $\begin{array}{l}\text { Level of cooperation with other companies } \\
\text { Existing level of infrastructure (facilities, equipment, transport) } \\
\text { Inventory level and stock (inventory and stock value) } \\
\text { Qualification level of employees }\end{array}$ \\
\hline
\end{tabular}


Table 2

Business management areas.

\begin{tabular}{lll}
\hline Value chain & 1 & $\begin{array}{l}\text { Design management } \\
\text { Production and service provision } \\
\text { management }\end{array}$ \\
& 3 & $\begin{array}{l}\text { Purchasing and logistics management } \\
\text { Marketing management/customer } \\
\text { relationship }\end{array}$ \\
& & People management \\
Value chain support & 6 & Infrastructure management \\
area & 7 & Knowledge management \\
& 8 & Financial management \\
& 9 & Strategy management \\
& 10 & Quality management \\
& 11 & Environmental management \\
& 12 & Occupational, health and safety management \\
Cross-sectional areas & 13 & R\&D\&I management \\
& 14 & Social responsibility management \\
\hline
\end{tabular}

- Vector of the characterizing factor (Input vector, $\mathcal{I}$ ): It contains the 23 characterizing factors $\left(X_{j}\right)$ each one evaluated with a natural number in the [1-5] range.

- Vector of the management areas (Output vector $\mathcal{O}$ ): It contains the 14 management areas $\left(A_{i}\right)$, classified with a natural number in the [1-14] range, that represent the importance of these management area. Lower number represents higher importance. The elements of this vector have to fulfill the following equation:

$\operatorname{Imp}\left(A_{i}\right) \neq \operatorname{Imp}\left(A_{j}\right), \quad \forall i \neq j$

The initial case base (Fig. 2) was generated starting from the input of 6 experts. Every expert was given a questionnaire to evaluate some companies. This initial case base had a total amount of 48 cases.

Currently, the database has evolved from data collected from the self-assessment of real companies, after a revision from an expert. Moreover, the system allows adding new cases without the need for a self-assessment of a company. An expert can easily add new startup cases to the case-base.

\subsection{Description of the general module}

The CBR is integrated into a general module. This module is responsible for receiving the input data, processing it and producing the output to the users interface, as an ordered list of management areas according to their importance to the company.

This module requires three actors: the system, the user of the company and the expert. The system is responsible for storing, processing and synthesizing information. The user of the company provides the information for its self-assessment obtaining a solution and can provide new possible solutions to the problem. The expert will decide whether cases are added or not to the case-base. The expert adds new knowledge to the case base obtained from the solutions of the self-assessment or adds a new solution that he decides to contribute.

The general module executes the following process whenever a company makes a self-assessment or an update of its characterizing factors (Fig. 3):

- It reads the characterizing input factors, from a survey that shows the 23 characterizing factors each one evaluated in [1-5] range.

- It calculates similarities between the new case and the casebase and recovers the most similar. Similarity is obtained as described in Section 3.4.1.

- The output, a list of ordered management areas is obtained according to the next steps:

- If there are several similar cases, it chooses the one with the highest similarity.

- If there is a tie, it chooses the case corresponding to a company from the same sectors.

- The ordered list that belongs to the case chosen is shown to the user.

- If the user disagrees with this suggested order, it is possible to propose a new solution.

- All the possible solutions are stored in the base of new cases: the CBR solution, the solution proposed by the company, if applicable, and a solution from an evaluation by an external expert.

An expert can update the case-base reusing the information stored in the base of new cases, executing the revise step of the $\mathrm{CBR}$. For the reuse of this information, the expert can choose one of the proposed solutions (CBR, company solution or external evaluation, if they exist) or propose a new classification.

The general module achieves all the required goals:

- It can guide the companies in the assessment and improvement in its most important management areas.

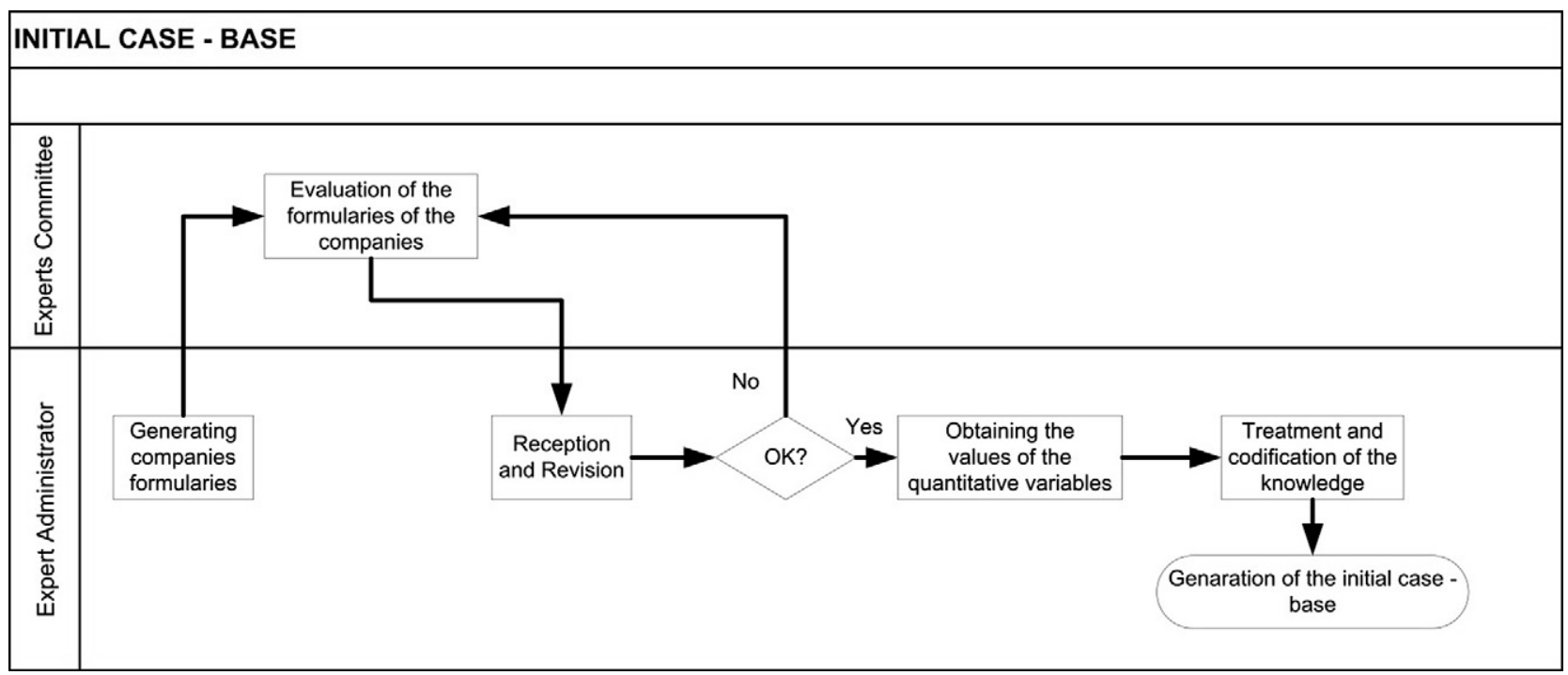

Fig. 2. Generation scheme to the initial case-base. 


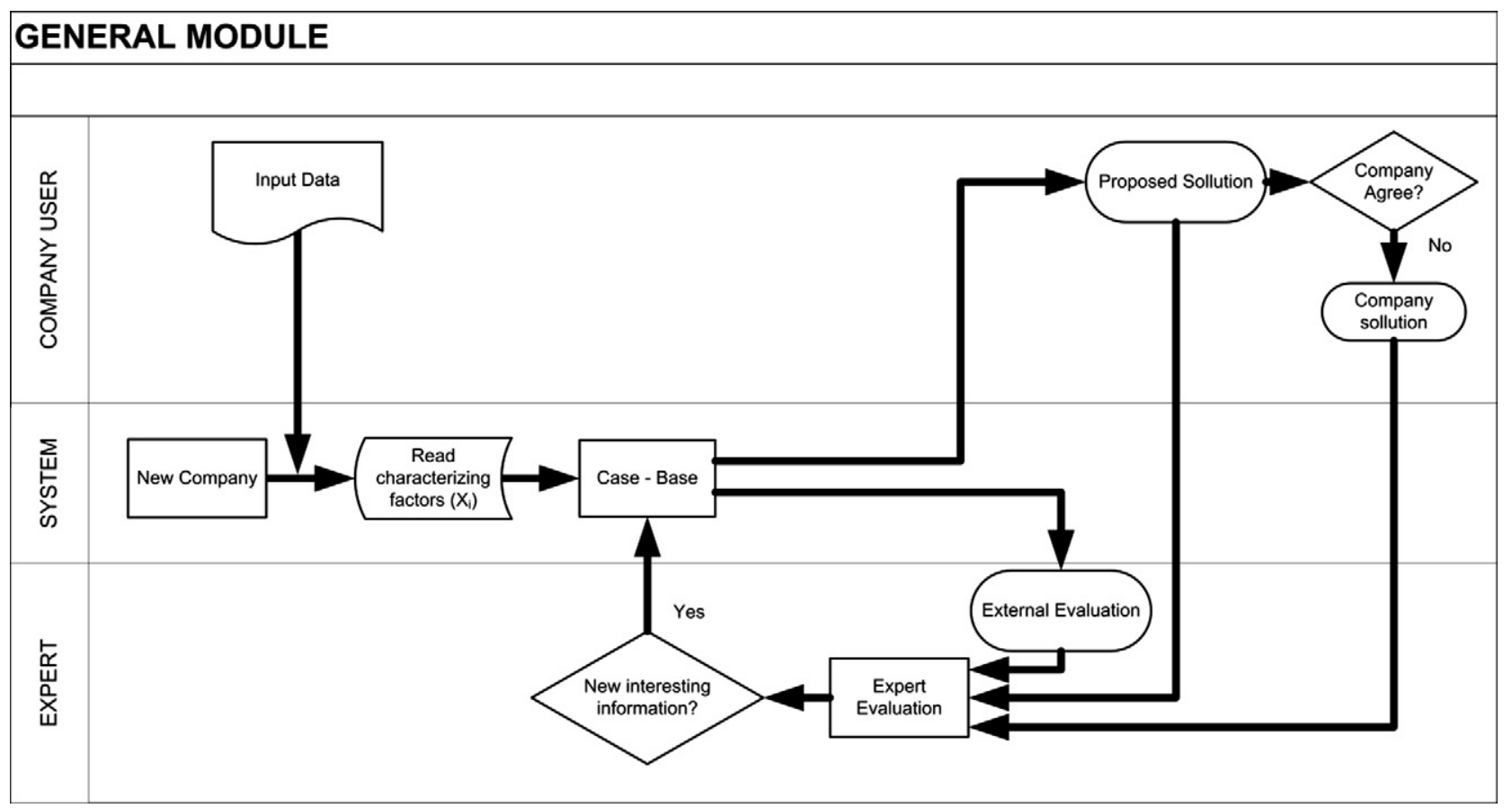

Fig. 3. Process diagram of the general module.

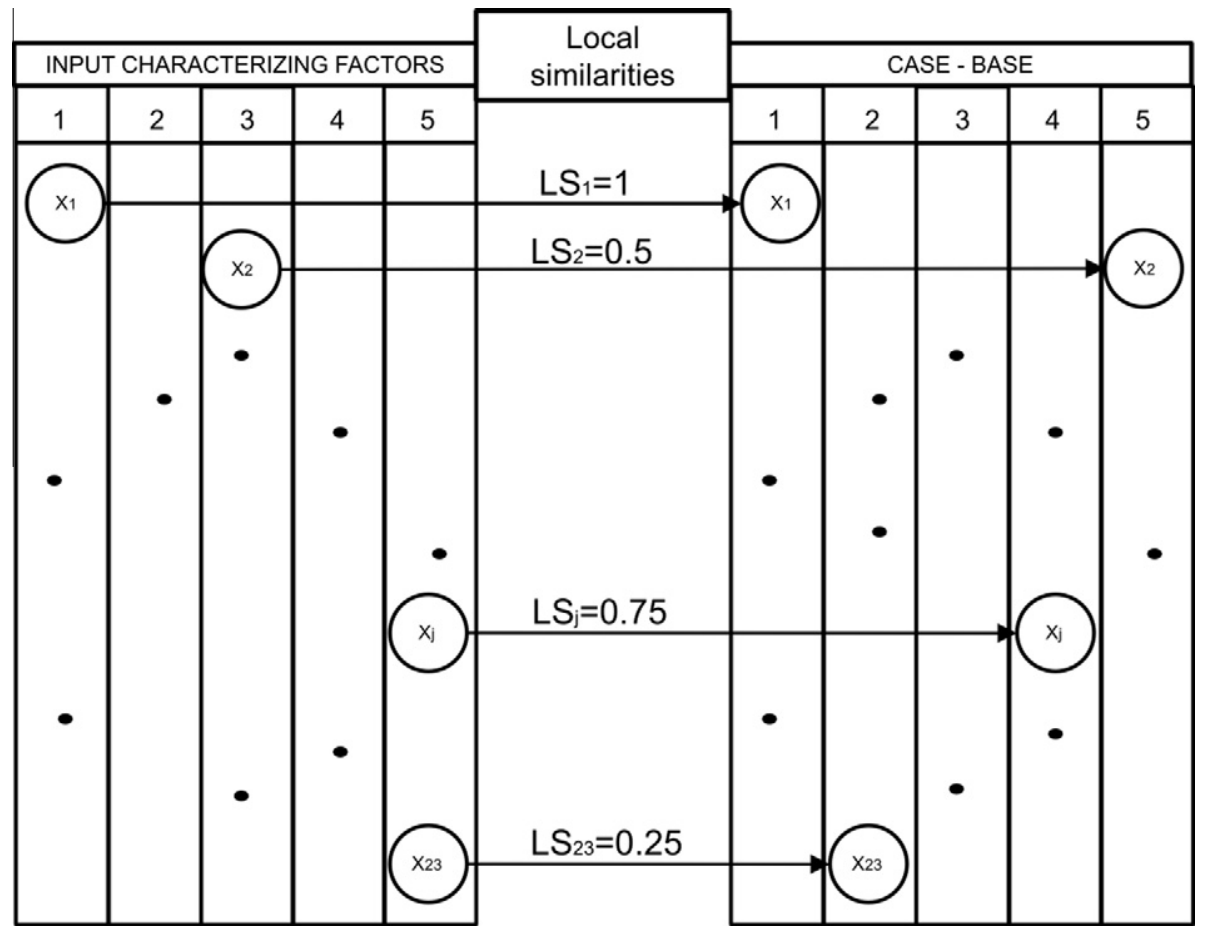

Fig. 4. Graphical representation of the similarity calculation.

- It can self-learn from the experience obtained from the companies evaluated.

\subsubsection{Obtaining the similarity between cases}

The global similarity represents how a new case with another of the case-base is similar. According to the CBI hypothesis (Hullermeier, 1999), it is necessary to retrieve useful information to evaluate a new case. Moreover, global similarity can provide us information about the reliability of the solution provided by the CBR.
This global similarity (GS) is defined as a weighted sum of local similarities $\left(L S_{i}\right)$, using weights $\left(\alpha_{i}\right)$ obtained during the identification of the characterizing factor as input variables. Therefore, the global similarity can be obtained as:

$G S=\Sigma\left(\alpha_{i} \cdot L S_{i}\right), \quad \forall i \exists \mathbb{Z}=[1-23]$

$L S_{i}$ represents the similarity, in P.U., of a characterizing factor between two cases. It is related with the distance of every characterizing factor between different cases. Obtained $L S_{i}$ takes into account that the assessment of every factor was done by stages in a [1-5] 
Table 3

Matrix for local similarity calculation.

\begin{tabular}{llllll}
\hline \multirow{2}{*}{ Input case } & \multicolumn{5}{l}{ Case of case-base } \\
\cline { 2 - 6 } & 1 & 2 & 3 & 4 & 5 \\
\hline 1 & 1 & 0.75 & 0.5 & 0.25 & 0.1 \\
2 & 0.75 & 1 & 0.75 & 0.5 & 0.25 \\
3 & 0.5 & 0.75 & 1 & 0.75 & 0.5 \\
4 & 0.25 & 0.5 & 0.75 & 1 & 0.75 \\
5 & 0.1 & 0.25 & 0.5 & 0.75 & 1 \\
\hline
\end{tabular}

range, and it is assumed that for a particular factor, closer scenarios have similar characterizing factors value. It is represented graphically in Fig. 4. A linear separation between the scenarios has been considered.

$L S_{i}$ is defined in [1-0.1] range, 1 being the highest possible similarity between cases. For maximum distance between characterizing factors 0.1 of similarity is chosen, due to maximum distance does not imply a zero similarity. It only implies a low similarity.
Every local similarity $\left(L S_{i}\right)$ between the values corresponding to the same factor $(i)$ in two different cases, is calculated with the weight matrix shown in Table 3, where the horizontal axis represents the factors of the company and the vertical axis the factors of the case to compare.

Sometimes, two or more solutions in the case-base with the same highest global similarity with respect to a new case can be found. To choose the best solution, a sector of the company has been integrated to calculate the global similarity.

The coincidence of business sector is represented by the variable $\delta_{m}$. It can take the binary value 0 , to indicate that the comparison is made with a company in other sector, or 1 to represent both companies in the same sector.

Now, the global similarity $\left(G S_{w}\right)$ is obtained as:

$G S_{w}=\left(1-w_{\text {sector }}\right) \cdot\left(\Sigma\left(\alpha_{i} \cdot L S_{i}\right)\right)+w_{\text {sector }} \cdot \delta_{m}$

$w_{\text {sector }}$ represents the importance of two companies that are in the same sector. This parameter can be obtained experimentally.

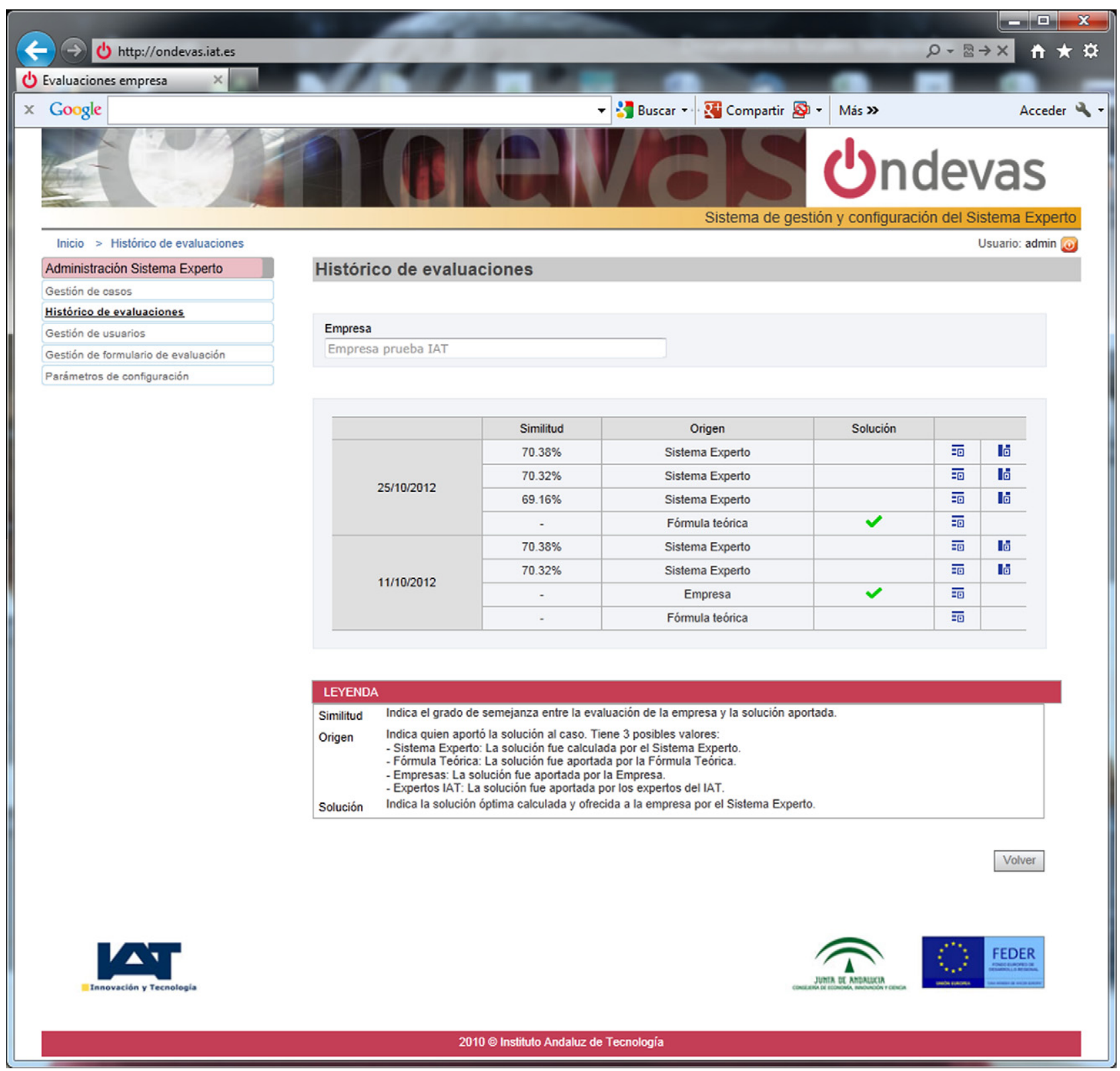

Fig. 5. GUI of the expert administrator. 


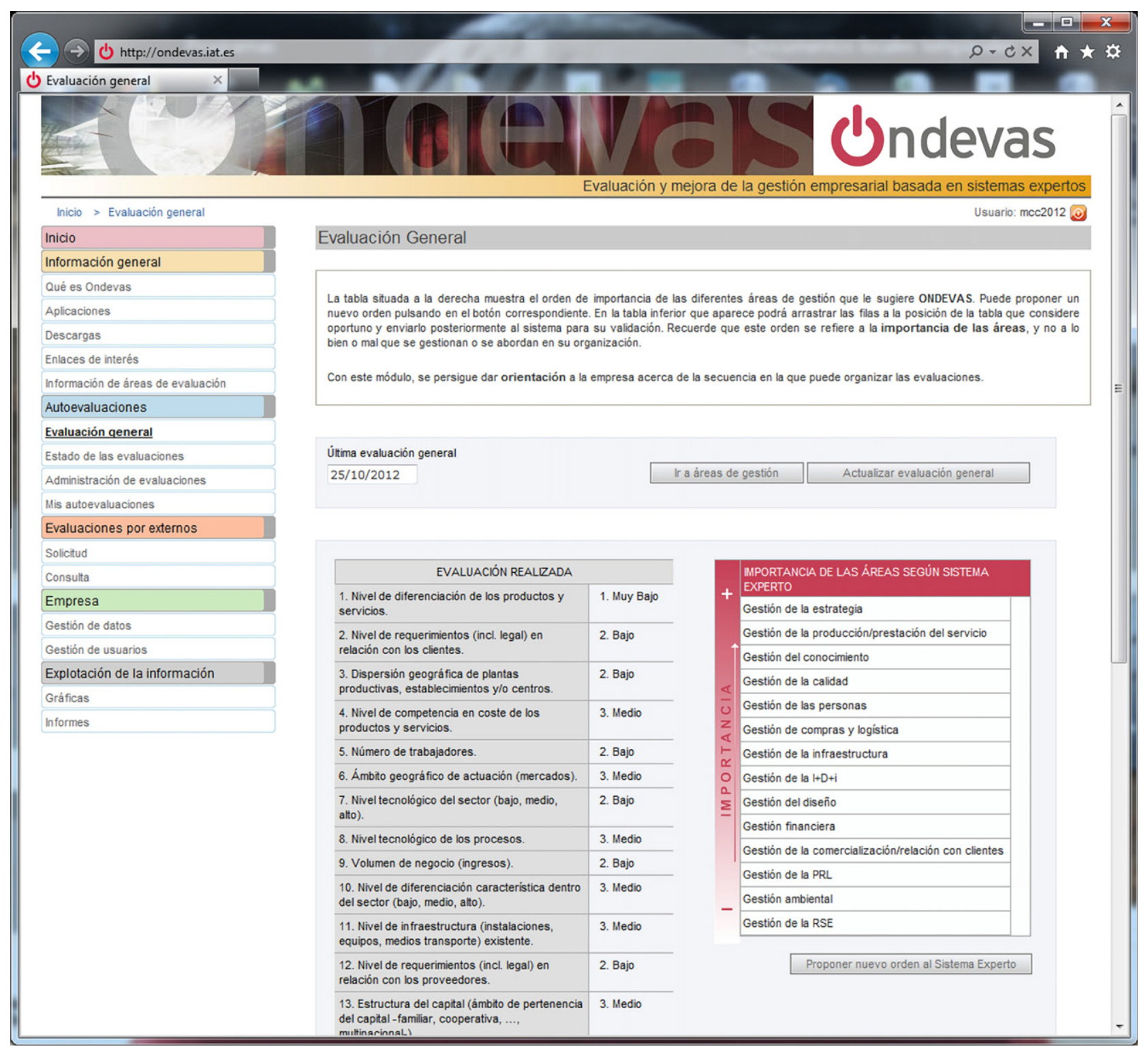

Fig. 6. GUI of the company.

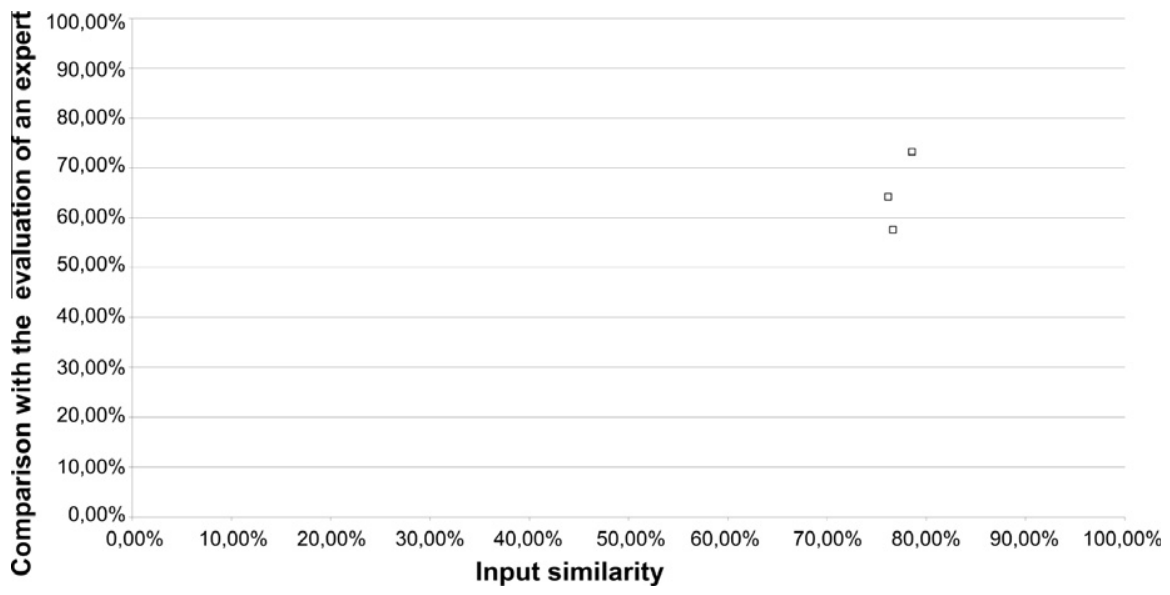

Fig. 7. Similarity of an example case and its three most nearest solutions. 


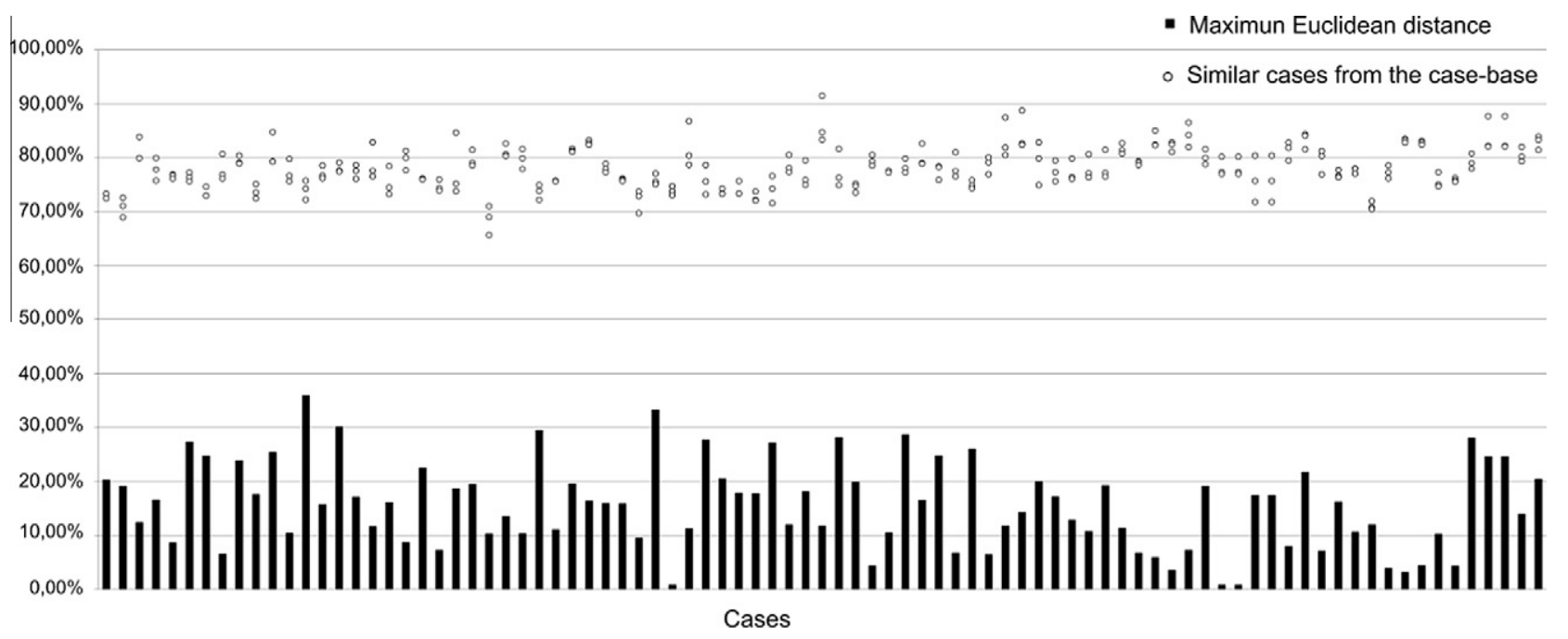

Fig. 8. Percentage of total values based on the positions that have changed.

All decisions previously considered $\left(5 \%\right.$ for $\left.w_{\text {sector }}, \alpha_{i}, \ldots\right)$ are considered as parameters. Due to it, the proposed system permits a modification these values to an expert, to adapt the calculations to the characteristics of the base case.

\section{Results}

The system is currently fully working. It is used for the assessment of Spanish companies. It has been in production since early 2011. It is accessible through a web based graphical interface (Figs. 5 and 6, http://ondevas.iat.es).

During this working time, the system has proven to be robust, performing well.

This section summarizes the most relevant results obtained with the proposed system.

\subsection{Comparison of the similarity between input and output vectors}

To check the similarity between cases, i.e., if the CBI hypothesis is valid for our application, it will make a comparison between input and output similarities.

In this experiment, 87 different new cases have been considered, obtained from the self-assessment of the companies. For each of these cases, we retrieve the three more similar cases found in the case-base, according to its characterizing parameters (inputs).
As an example, Fig. 7 shows the result of this comparison in a particular case. This figure sums-up the input and output similarities from the three retrieval cases from the case-base. $X$-axis represents the similarity between input vector $\mathcal{I}$ of the case under study and the three best cases proposed by the CBR system. $Y$-axis represents the similarity between the output vector $\mathcal{O}$ of the three best cases proposed by the CBR system and the output vector $\mathcal{O}$ proposed by an expert committee.

Fig. 8 depicts two similarities: On the one hand, circular dots represent the similarity of the each input vector $\mathcal{I}$ and the three base cases. In all cases the average similarity can be seen to be around $80 \%$. It means that for all the cases under study, the system has always found cases with high similarity.

On the other hand, each vertical bar represents the maximum Euclidean distance obtained among the output vectors $\mathcal{O}$ for every case. It means that for all the cases proposed as a solution for a given case, the output vectors $\mathcal{O}$ are close. It would be understood as a representation of the dispersion. It is shown that this value is small, below $40 \%$.

As it can be seen, similar inputs produce similar outputs, according to $\mathrm{CBI}$ hypothesis.

Furthermore, the results show that the cases are similar to the responses obtained by the expert committee. Due to this, we can conclude that the results provided by the CBR are valid for the proposed system.

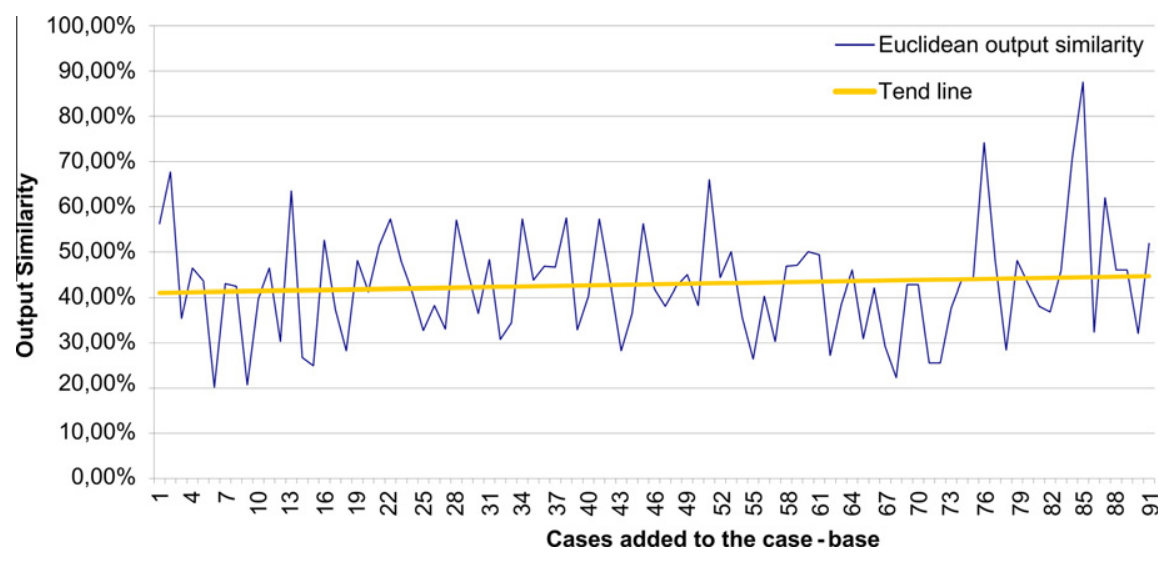

Fig. 9. Similarity between inputs and outputs. 


\subsection{Improving the results with an increment of cases}

As discussed above, the initial base case obtained with the evaluation of an expert, had a reduced size. It only contains 48 cases. Due to the base case being small, it does not cover enough cases.

Fig. 9 shows the similarity evolution between cases, when it increases the number of cases of the case-base.

These results have been obtained by adding to the initial casebase the results of the first 90 self-evaluations of the companies. As it can be seen, while most validated cases include the case-base, we can obtain the most accuracy from the system, in comparison with an expert evaluation.

It is important, therefore, that the case-base cover a sufficient number of cases to provide correct results.

It is important to consider that increasing the case-base, improves the accuracy, but it also increases the complexity of similar retrievals, and consequently increasing the time to access to the cases.

Empirically we have determined that 1000 cases provide a good trade-off between accuracy and access time, allowing good adaptability to changes in the management of companies.

\section{Conclusions and future work}

In this paper a new module for an evaluation and categorization of the business management areas of a company is presented. This module provides guidance for companies and allows a simple way of knowing which parts of the overall management are most important for a specific organization. Once companies have this kind of assessment, the company may prioritize its efforts and make local specific evaluations in its most important management areas. Due to an improvement in these areas, this may cause significant increases at the tactical level of an organization.

The module has been implemented in a web-based tool designed to support self-assessment to Spanish companies. The module is based on a CBR, which allows getting a dynamic response, with an easy adaptation to changes that occur in companies. Due to this, the proposed system avoids its obsolescence.

This system has been working for a year. The analysis of the results shows that it is reliable in comparison with the results provided by an expert committee.

We are working on applying the proposed system to every specific business areas as future work.

\section{Acknowledgments}

The authors thank the collaboration of the Andalusian Institute of Technology (IAT), which has offered the business data needed to carry out this work.

\section{References}

Ahmed, A. M., \& Abdalla, H. S. (2002). An intelligent system for performance measurement. Proceedings of the Institution of Mechanical Engineers Part B: Journal of Engineering Manufacture, 216.

Bititci, U., Turner, T., \& Begemann, C. (2000). Dynamics of performance measurement systems. International Journal of Operations and Production Management, 20(6), 692-704.
Brown, C., \& Gupta, U. (1994). Applying case-based reasoning to the accounting domain. International Journal of Intelligent Systems in Accounting Finance and Management, 3, 205-221.

Chen, L.-H., \& Hsiao, H.-D. (2008). Feature selection to diagnose a business crisis by using a real GA-based support vector machine: an empirical study. Expert Systems with Applications, 35(3), 1145-1155.

Conti, T. (2007). A history and review of the European Quality Award Model. The TQM Magazine, 19(2), 112-128.

Cook, W. D., \& Seiford, L. M. (1982). On the Borda-Kendall consensus method for priority ranking problems. Management Science, 28, 621-663.

De Carlo, J., \& Sterett, W. K. (1990). History of the Malcolm Baldrige National Quality Award. Quality Progress, 23(3), 21.

Engelbrecht, A. P. (2007). Computational intelligence: an introduction. John Wiley \& Sons. ISBN: 9780470035610.

Hullermeier, E. (1999). Toward a probabilistic formalization of case-based inference. In Vol. 1. Proceedings of the 16th international joint conference on artifical intelligence (IJCAI'99), Stockholm, Sweden (pp. 248-253).

Hüllermeier, E. (2007). Case-based approximate reasoning. In Theory and decision library. Springer. ISBN: 9781402056949.

Kawakita, J. (1986). The KJ method: seeking order out of chaos. Tokyo: Chookoronsha. ISBN: 4-12-001517-3.

Lam, C. Y., Ip, W. H., \& Lau, C. W. (2009). A business process activity model and performance measurement using a time series ARIMA intervention analysis. Expert Systems with Applications, Part 2, 36(3), 6986-6994.

Lin, Kuo-Ping, \& Pai, Ping-Feng (2010). A fuzzy support vector regression model for business cycle predictions. Expert Systems with Applications, 37(7), 5430-5435.

Lin, F., Yeh, C.-C., \& Lee, M.-Y. (2011). The use of hybrid manifold learning and support vector machines in the prediction of business failure. Knowledge-Based Systems, 24(1), 95-101.

Li, H., \& Sun, J. (2011). Predicting business failure using forward ranking-order casebased reasoning. Expert Systems with Applications, 38(4), 3075-3084.

Mavroidis, V., Toliopoulou, S., \& Agoritsas, C. (2007). A comparative analysis and review of national quality awards in Europe: development of critical success factors. The TQM Magazine, 19(5).

Miles, R.E., \& Snow, C.C. (2003). Organizational strategy, structure and process. In Stanford business books: Vol. 3, No. 3. ISBN: 0-8047-4840-3.

Mintzberg, H. (1979). The structuring of organizations: a synthesis of the research University of Illinois at Urbana-Champaign's Academy for Entrepreneuria Leadership Historical Research Reference in Entrepreneurship.

Mintzberg, H. (2010). Managing. Blackwell Publishing Inc. ISNN: 17446570.

Montani, S., Leonardi, G., \& Bramer, M. (2010). A case-based approach to business process monitoring. In Intelligence in theory and practice III. Boston: Springer.

Munder, S., \& Gavrila, D. M. (2006). An experimental study on pedestrian classification. IEEE Transactions on Pattern Analysis and Machine Intelligence, 28(11), 1863-1868.

Neely, A., Slater, J., Kennerley, M., Mills, J., Platts, K, Richards, H., et al. (2000) Performance measurement system design: developing and testing a process based approach. International Journal of Operations \& Production Management 20(10), 1119-1144.

Nikravesh, M. (2004). Soft computing-based computational intelligent for reservoir characterization. Expert Systems with Applications, 26, 19-38.

Porter, M. E. (2011). Competitive strategy: techniques for analyzing industries and competitors. Ingram. ISBN: 0-02-925360-8.

Pride, W. M., Hughes, R. J., \& Kapoor, J. R. (2009). Business (10th ed.). Cengage Learning. ISBN: 0324829558.

Shiu, S., \& Pal, S. K. (2004). Foundations of soft case-based reasoning. John Wiley \& Sons. ISBN: 0471086355.

van der Wiele, A., Williams, A. R. T., Dale, B. G., Carter, G., Kolb, F., Luzon, D. M., et al (1996). Self-assessment: a study of progress in Europe's leading organizations in quality management practices. International Journal of Quality $\mathcal{E}$ Reliability Management, 13(1), 84-104.

Velmurugan, T. (2011). A survey of partition based clustering algorithms in data mining: an experimental approach. Information Technology Journal, 10(3) 478-484.

Wu, S. X., \& Banzhaf, W. (2010). The use of computational intelligence in intrusion detection systems: a review. Applied Soft Computing Journal, 10(1) $1-35$.

Yeh, C.-C., Chi, D.-J., \& Hsu, M.-F. (2010). A hybrid approach of DEA, rough set and support vector machines for business failure prediction. Expert Systems with Applications, 37(2), 1535-1541.

Zink, K. J., \& Schmidt, A. (1998). Practice and implementation of self-assessment International Journal of Quality Science, 3(2), 147-170. 